\title{
Avoiding a red card: recommendations for a consistent standard of concussion management in professional football (soccer)
}

\author{
Vincent Gouttebarge (1) 1,2,3,4 Edwin A Goedhart, ${ }^{5}$ Emmanuel Orhant, ${ }^{6}$ \\ Jon Patricios
}

Compared with some collision/contact sports, concussions are relatively uncommon in professional football (soccer). ${ }^{1} \quad 2$ Nevertheless, professional football has been under repeated scrutiny because of questionable recognition and management (on-field and off-field) of concussions during several high-profile international and national competitions. Given the Concussion in Sport Consensus process has been ongoing for two decades, it is important that professional football adopt consistent policies that represent the highest standard of concussion care. ${ }^{1}$ We believe the current approach to concussion in some professional football competitions may warrant a red card. Being the world's highest profile sport, we acknowledge that football's apparent concussion management oversights may appear to be disproportionately exposed in both the medical and public eye. We also recognise that the Fédération Internationale de Football Association (FIFA) and many professional leagues have made many steps towards promoting highquality concussion care. Equally, however, variable policies exist that may

${ }^{1}$ FIFPRO (Football Players Worldwide), Hoofddorp, The Netherlands

${ }^{2}$ Amsterdam UMC, University of Amsterdam, Department of Orthopaedic Surgery, Amsterdam Movement Sciences, Meibergdreef 9, Amsterdam, The Netherlands

${ }^{3}$ Section Sports Medicine, University of Pretoria, Pretoria, South Africa

${ }^{4}$ Amsterdam Collaboration on Health \& Safety in Sports (ACHSS), Amsterdam UMC IOC Research Center of Excellence, Amsterdam, The Netherlands

${ }^{5}$ Royal Netherlands Football Association (KNVB), FIFA Medical Center of Excellence, Zeist, The Netherlands

${ }^{6}$ French Football Federation (FFF), Clairefontaine Medical Centre, FIFA Medical Center of Excellence, Clairefontaine, France

${ }^{7}$ Wits Sport and Health (WiSH), School of Clinical Medicine, Faculty of Health Sciences, University of the Witwatersrand, Johannesburg-Braamfontein, South Africa

Correspondence to Prof. Vincent Gouttebarge, Orthopaedic Surgery, Amsterdam University Medical Centres, Amsterdam, The Netherlands; v.gouttebarge@amsterdamumc.nl compromise athlete care, and the sports profile and popularity should be used to promote optimal concussion care and educate millions. As clinicians who have been working in professional football for over 100 cumulated years, we propose a series of measures to improve the recognition and management of concussion across professional football.

\section{NECESSARY MEASURES}

\section{Mandatory education}

Educating players, staff and officials regarding concussion should play a significant role in improving concussion recognition and management. This is already implemented in a few football leagues such as Major League Soccer (MLS), and trialled successfully by FIFPRO (Football Players Worldwide) for the FIFA Women's World Cup 2019 in France. ${ }^{3}$ Advocated by medical professionals, annual education should be facilitated in all football leagues by stakeholders and be mandatory. ${ }^{45}$ Such annual and mandatory education could reduce players misrepresenting concussive symptoms and convince (if needed) staff and officials that players' welfare should always be prioritised.

Application of 'If in doubt, sit them out' Any professional footballer with a suspected concussion should immediately be assessed on-field, and if suspicion persists, removed from the field of play straight away. ${ }^{1}$ The decision to remove a player should be quick with the more structured evaluation being off-field. In order to protect the players' health, 'If in doubt, sit them out' should be systematically applied as it is in other sports (eg, rugby union). This concept is supported by a recent Team Physician Consensus Statement. ${ }^{3}$

\section{Access to video footages and independent spotter}

As concussion recognition is often impaired from the side line, providing medical teams with access to match video footage (including replay and slow motion) should improve the recognition of concussion. A trained independent spotter, in contact with both medical teams and having access to the match footage, could be of additional assistance. Endorsed by football physicians, this approach has been utilised recently by FIFA for their Club World Cup 2019 Qatar, the UEFA for their European Championship 2020 and by MLS, and will be implemented by FIFA for their World Cup 2022 Qatar. $^{3} 4$ The medical team and spotter should be educated to detect the video signs described in two recent consensus statements as highly predictive of a concussion diagnosis (when seen in combination with a direct or indirect head blow). ${ }^{6}$ These signs include lying motionless, motor incoordination, impact seizure, tonic posturing, no protective action and blank/vacant look. ${ }^{36}$ We advocate the use of qualified healthcare providers as independent spotters. As long as competitions are broadcast, costs should not be a major barrier for professional football. Professional leagues with less resources may have more challenges with acquiring sideline access to video footage.

Time window for concussion assessment and related alteration of the laws of the game

Defined by the International Football Association Board (IFAB), the current laws of the game provide the medical team with a 3 min window for the on-field evaluation of a potentially concussed player. This is inadequate because (1) more time is needed for a thorough concussion assessment (international consensus recommends at least $10 \mathrm{~min}$ ) and (2) the environment is conducive to interference by other players, staff and officials. ${ }^{1}$ Moreover, a longer, off-field evaluation in a distraction-free environment will allow for inclusion of the video review to inform a comprehensive decision-making process. An alteration of the laws of the game is needed that allows for more time to evaluate players while the game continues. Widely introduced in many high-speed collision sports as well as in cerebral palsy football, and advocated by football physicians, temporary concussion substitution should be trialled and evaluated in professional football. ${ }^{47}$ Such a temporary concussion substitution would facilitate less disruption of the game, maintain competitive equity during match play, and allow a more thorough evaluation than the current on-field process. 


\section{Time window for return to football} competition

According to the latest consensus statement on concussion and its graduated return-tosport protocol, a concussed professional footballer who has undergone serial clinical evaluations and remained asymptomatic, should return to football competition on the sixth recovery day at the soonest. ${ }^{1}$ Consequently, a player concussed in a weekend match should not return to football competition in the subsequent midweek match.

\section{Documented clearance by team} physician

The team physician should supervise and document the progression of a concussed player through the graduated return-to-sport protocol, especially the medical clearance to progress to unrestricted full contact practice. ${ }^{13}$ As in other sports, a multidisciplinary approach by a clinical support team (eg, neuropsychologist, neurologist, vestibular therapist) might be of assistance and should be accessible. $^{38}$

\section{AVOIDING A RED CARD}

The aforementioned measures should not be considered in isolation but in combination as a holistic approach to complete concussion care. The professional football stakeholders (eg, leagues, players unions) remain responsible for the implementation of these measures. Additional standards introduced in other sports (eg, baseline assessments, neurocognitive evaluations, the assistance of an independent physician, a compliance and sanction committee) should also be considered and evaluated for effectiveness in reducing concussions and their consequences within professional football. ${ }^{3}$ For a high profile, well-resourced sport, with an opportunity and responsibility to educate globally, a consistent approach to concussion recognition and management is needed throughout professional football to avoid a red card.

Twitter Vincent Gouttebarge @vgouttebarge and Jon Patricios @jonpatricios

Contributors VG conceptualised and drafted the initial version of the manuscript, with critical review provided by all authors. All authors read and approved the final version of the manuscript.

Funding The authors have not declared a specific grant for this research from any funding agency in the public, commercial or not-for-profit sectors.

Competing interests JP is an editor of the British Journal of Sports Medicine, a Board member of the Concussion in Sport Group (CISG) and on the scientific committee for the International Consensus Conference on Concussion in Sport.

Patient consent for publication Not applicable.

Provenance and peer review Not commissioned; externally peer reviewed.

\section{(0) OPEN ACCESS}

Open access This is an open access article distributed in accordance with the Creative Commons Attribution Non Commercial (CC BY-NC 4.0) license, which permits others to distribute, remix, adapt, build upon this work non-commercially, and license their derivative works on different terms, provided the original work is properly cited, appropriate credit is given, any changes made indicated, and the use is non-commercial. See: http:// creativecommons.org/licenses/by-nc/4.0/.

(c) Author(s) (or their employer(s)) 2021. Re-use permitted under CC BY-NC. No commercial re-use. See rights and permissions. Published by BMJ.

\section{Check for updates}

To cite Gouttebarge V, Goedhart EA, Orhant E, et al. $\mathrm{Br} J$ Sports Med Epub ahead of print: [please include Day Month Year]. doi:10.1136/bjsports-2021-104796

Accepted 17 September 2021

Br J Sports Med 2021:0:1-2.

doi:10.1136/bjsports-2021-104796

\section{ORCID iDs}

Vincent Gouttebarge http://orcid.org/0000-0002-01264177

Jon Patricios http://orcid.org/0000-0002-6829-4098

\section{REFERENCES}

1 McCrory P, Meeuwisse W, Dvořák J, et al. Consensus statement on concussion in sport-the 5 th international conference on concussion in sport held in Berlin, October 2016. Br J Sports Med 2017:51:838-47.

2 Waldén M, Hägglund M, Orchard J, et al. Regional differences in injury incidence in European professional football. Scand I Med Sci Sports 2013;23:424-30.

3 Herring S, Kibler WB, Putukian M. Selected issues in sport-related concussion (SRC|mild traumatic brain injury) for the team physician: a consensus statement. Br J Sports Med 2021

4 Gouttebarge V, Ahmad I, lqbal Z, et al. Concussion in European professional football: a view of team physicians. BMJ Open Sport Exerc Med 2021;7:e001086.

5 Rosenbloom C, Broman D, Chu W, et al. Sport-related concussion practices of medical team staff in elite football in the United Kingdom, a pilot study. Science and Medicine in Football 2021:9:1-9.

6 Davis GA, Makdissi M, Bloomfield P, et al. International consensus definitions of video signs of concussion in professional sports. Br J Sports Med 2019;53:1264-7.

7 International Federation of Cerebral Palsy Football. IFCPF unveils new temporary concussion substitution (TCS) policy. 2019-12-10. Available: https://www.ifcpf. com/news/ifcpf-unveils-new-temporary-concussionsubstitution-\%28tcs\%29-policy

8 World Rugby. Concussion Guideline. Available: https:// www.world.rugby/news/612885 